\title{
A gestão por competência e as funções de recursos humanos: estudo de caso na Universidade Federal do Ceará (UFC)
}

\section{The competency management and human resources functions: a case study at the Federal University of Ceará (UFC)}

\author{
Marcos Antônio Martins Lima ${ }^{1}$ \\ Ioneiry Viana Lima ${ }^{2}$
}

\section{Resumo}

A forma como as organizações realizam a gestão de pessoas passa por grandes transformações em todo o mundo. A inadequação dos modelos tradicionais de gestão de recursos humanos que são originários dos movimentos da administração científica, os quais tinham o controle como referencial para manter a relação entre as pessoas e a organização, motivaram tais mudanças, levando à adoção de um novo conjunto de conceitos que melhor integram a gestão de pessoas, com o intento estratégico organizacional através da discussão das competências. Essa tendência, estimulada pela gestão por competência, está se consolidando nas organizações privadas e, por meio legal, inserindo-se também nas instituições públicas. 0 desenvolvimento deste trabalho inicia-se pela breve revisão bibliográfica que permitiu traçar um cenário teórico sobre a gestão de pessoas, destacando a gestão por competência e, posteriormente, evidenciando sua aplicação no setor público. Foram enfatizados no apanhado teórico quatro subsistemas de recursos humanos: recrutamento e seleção (R\&S), treinamento e desenvolvimento (T\&D), avaliação de desempenho, e remuneração ou cargos e salários (C\&S). A pesquisa buscou investigar a operacionalização da gestão de pessoas desenvolvida na Universidade Federal do Ceará (UFC). O objetivo principal foi verificar na UFC, uma instituição pública de ensino superior, se os subsistemas de gestão de pessoas, da forma como atualmente se apresentam, estão alinhados às diretrizes propostas pela abordagem

Doutor em Educação pela Universidade Federal do Ceará. E-mail: marcos.a.lima@terra.com.br. Fone/Fax: (85) 3366-7677.

2 Especialista em Estratégia e Gestão Empresarial pela Universidade Federal do Ceará. E-mail: ioneirylima@ufc.br. Fone/Fax: (85) 33667883. 
da gestão por competências. Por meio de um estudo de caso exploratório, obtevese a percepção dos servidores técnico-administrativos lotados na Superintendência de Recursos Humanos da UFC sobre os quatro subsistemas de gestão de pessoas, alcançando como resultados quantitativos e qualitativos algumas interações e dissonâncias entre os subsistemas anteriormente referidos e as diretrizes propostas pela gestão por competência.

Palavras-chave: Gestão de pessoas. Gestão por competências. Setor público.

\section{Abstract}

The way organizations perform the management of people undergoes great changes in the world. The inadequacy of traditional models of human resource management that are originating in the scientific management movement, which had control as a reference to maintain the relationship between people and organization, motivated these changes leading to adoption of a new set of concepts that best integrate the management of people with the organizational strategic intent through discussion skills. This trend encouraged by the management competence is consolidating in private organizations and, through legal, inserting also in public institutions. The development of this work begins with the literature review that allowed us to outline a theoretical scenario about people management, competence management by highlighting and then showing its application in the public sector. Emphasized, in the theoretical overview, four human resources subsystems: recruitment and selection ( $R$ \& S) training and development ( $T$ \& D), performance evaluation, and jobs and salaries or compensation (C\&S). The research sought to investigate the deployment of personnel management currently developed in the Federal University of Ceará (UFC). The main objective was to verify the UFC, a public institution of higher education, if the management subsystems of people, the way you currently have, are aligned to the guidelines proposed by the approach of competency management. Through an exploratory case study obtained the perceptions of technical and administrative server, crowded by the Superintendent of Human Resources of the UFC, on the four subsystems of personnel management, and achieving results, quantitative and qualitative, some interactions and dissonances between the subsystems mentioned above and the guidelines proposed by the management competence.

Keywords: People management. Competency management. Public sector.

\section{Introdução}

Em meio às alterações ocorridas na forma como as organizações realizam a gestão de pessoas, motivadas pela inadequação dos modelos 
tradicionais de gestão de recursos humanos, os quais são originários dos movimentos da administração científica, observa-se, na história recente, a existência de um novo conjunto de conceitos que melhor explicam a relação entre a organização e as pessoas. Percebe-se, então, com maior clareza, a possibilidade de integrar a gestão de pessoas com o intento estratégico da empresa ou instituição pública através da discussão das competências humanas e organizacionais.

A evolução do conceito de competência procura valorizar o profissional com base em suas capacidades e estimular o desenvolvimento destas, além de reconhecer a importância da atuação dos indivíduos no desempenho de suas atividades e, consequentemente, na obtenção de resultados para a organização.

O problema a ser averiguado por esta pesquisa traduz-se em investigar a operacionalização do gerenciamento de pessoas atualmente desenvolvida na Universidade Federal do Ceará (UFC), tendo como ênfase os subsistemas de gestão de pessoas implementados nessa Instituição de Ensino Superior (IES). O objetivo da pesquisa proposta é verificar, na UFC, se tais subsistemas, da forma como atualmente se apresentam, estão alinhados com as diretrizes propostas pela abordagem da gestão por competências.

Metodologicamente, esta pesquisa exploratória foi realizada por meio de um estudo de caso, utilizando como principal instrumento de coleta de dados um questionário estruturado contendo questões objetivas sobre os quatro subsistemas de gestão de pessoas: recrutamento e seleção (R\&S), treinamento e desenvolvimento (T\&D), avaliação de desempenho, e remuneração ou cargos e salários (C\&S), além de um espaço destinado a comentários dos respondentes, os quais são servidores lotados na Superintendência de Recursos Humanos da UFC, caracterizando este estudo como quantitativo e qualitativo.

\section{Gestão de pessoas}

Agestão de pessoas passou por grandes alterações de abordagens até conquistar o atual foco estratégico. Muitos autores se referem à 
gestão de pessoas como Administração de Recursos Humanos (ARH). Para Milkovich e Boudreau (2009, p. 19), entende-se ARH como "uma série de decisões integradas que formam as relações de trabalho; sua qualidade influencia diretamente a capacidade da organização e de seus empregados em atingir seus objetivos".

\subsection{As funções de recursos humanos}

De acordo com Marras (2000), a área de Recursos Humanos $(\mathrm{RH})$, organicamente, é composta por um conjunto de subsistemas que respondem individualmente por cada uma das funções da área de recursos humanos.

Ulrich (1998) sintetiza que, ao final dos anos 1970, os autores sobre RH definiam como atividades principais as seguintes: contratação, desenvolvimento, avaliação e recompensas. As especialidades e funções de $\mathrm{RH}$ - ou seja, os subsistemas - surgiram dentro da empresa à medida que começaram a ser vistas de uma forma mais estratégica: contratação, decorrente da crença de que poderia ocorrer melhor adequação dos funcionários aos cargos e consequente melhoria no seu desempenho se eles passassem por testes e avaliações; treinamento, por meio do qual os funcionários poderiam desenvolver habilidades necessárias ao melhor desempenho no seu cargo; setor de remuneração, através do qual seria possível motivar os funcionários e levá-los a um desempenho mais elevado; e sistemas de avaliação, surgidos da necessidade de estabelecer comportamentos e resultados esperados dos funcionários para transformar as metas gerenciais em suas metas.

Para o autor, os subsistemas de desenvolvimento, recrutamento e contratação, treinamento e formação, as recompensas e reconhecimento, a gestão de desempenho, dentre outras atividades e práticas de $\mathrm{RH}$ precisam de um contínuo aprimoramento.

Para fins desta pesquisa, serão enfocados apenas alguns dos subsistemas relacionados. 


\subsubsection{Subsistema de recrutamento e seleção (R\&S)}

Também conhecido como subsistema de provisão, o subsistema de recrutamento e seleção, de acordo com Marras (2000, p. 65), é responsável pela captação e triagem de profissionais no mercado e pela seleção e encaminhamento de profissionais para a empresa. Conceitualmente, o recrutamento de pessoal "tem por finalidade a captação de recursos humanos interna e externamente à organização objetivando atender as necessidades dos clientes internos da empresa”.

Segundo Milkovich e Boudreau (2009), as evidências mostram que as organizações não avaliam com muita atenção suas atividades de recrutamento e seleção. Assim, com esse subsistema, a empresa terá que investir muito mais em treinamento para os novos funcionários.

\subsubsection{Subsistema de treinamento e desenvolvimento (T\&D)}

O treinamento tem se tornado cada vez mais imprescindível ao sucesso das organizações. Conceitualmente, de acordo com Marras (2000), treinamento é o processo de assimilação cultural em curto prazo, que tem como objetivo transmitir ou reciclar conhecimentos, habilidades ou atitudes direcionadas à execução de tarefas ou à otimização do trabalho.

Bohlander e Snell (2009) relacionam do idioma inglês as expressões know-ledge, skills, abilities and other factors, traduzidas e sintetizadas em três palavras: conhecimentos, habilidades e atitudes (CHA), e informam que o fortalecimento e desenvolvimento dessas variáveis são extremamente necessários ao indivíduo para lidar com as rápidas mudanças tecnológicas que levam a novos processos e sistemas de trabalho.

Milkovich e Boudreau (2009) enfatizam que o desenvolvimento das pessoas e as atividades de treinamento estão entre as atribuições mais rotineiras, porém, mais caras da ARH. Tais atividades têm por finalidade melhorar as habilidades já existentes e ensinar novas, buscando impactar nas atitudes dos empregados. 
Segundo Bohlander e Snell (2009), muitos especialistas fazem a distinção entre treinamento e desenvolvimento, especificando que este é mais dirigido para ampliar as habilidades dos indivíduos para futuras responsabilidades e aquele é mais focalizado e apontado para questões concernentes a desempenho de curto prazo.

\subsubsection{Subsistema de avaliação de desempenho}

Marras (2000, p. 173) conceitua o desempenho humano como "o ato ou efeito de cumprir ou executar determinada missão ou meta traçada previamente". Tal desempenho é diretamente proporcional a duas condições humanas: o querer fazer, que explicita o desejo endógeno de realizar, ou seja, a motivação; e o saber fazer, isto é, a condição cognitiva e experiencial que torna possível o indivíduo realizar com eficiência e eficácia alguma coisa.

Nesse contexto, um instrumento a ser utilizado é a avaliação de desempenho, que permite ao administrador mensurar os resultados obtidos por um empregado ou por um grupo em período e área específicos: seus conhecimentos, metas, habilidades etc.

Segundo o autor, avaliação de desempenho é um instrumento extremamente valioso e importante na $\mathrm{ARH}$, na medida em que evidencia o retorno recebido pela organização como resultado de um investimento realizado numa trajetória profissional. Tal avaliação foi criada para acompanhar o desenvolvimento cognitivo dos empregados durante sua permanência na organização e medir seu nível de CHA.

Para Bohlandere Snell (2009), do ponto de vista do desenvolvimento individual, a avaliação fornece o feedback fundamental para identificar os pontos fortes e fracos dos funcionários e aprimorar o desempenho. $O$ processo de avaliação possibilita identificar questões a serem discutidas, buscando eliminar qualquer problema potencial e estabelecer novas metas, de modo a atingir um alto desempenho.

Segundo os autores, as abordagens mais novas de avaliação de desempenho enfatizam o treinamento, o desenvolvimento e os planos 
de crescimento para os funcionários, em vez de simplesmente avaliar seu desempenho passado.

\subsubsection{Subsistema de remuneração ou cargos e salários (C\&S)}

Os funcionários sempre desejam uma remuneração justa e à altura de suas capacidades e expectativas. Para Bohlander e Snell (2009), o pagamento fornece aos funcionários uma recompensa quantificável por seus serviços, bem como uma fonte de reconhecimento e subsistência. O sistema de remuneração inclui todas as formas de pagamento e recompensas aos funcionários pelo desempenho de seu trabalho.

Os autores esclarecem que a remuneração direta abrange: ordenados e salários do funcionário, incentivos, bonificações e comissões. A remuneração indireta abrange os vários benefícios oferecidos pelas empresas, como programas de reconhecimento do funcionário, atividades gratificantes, suporte da empresa, ambiente de trabalho e horário de trabalho flexível para acomodar as necessidades pessoais.

Para Milkovich e Boudreau (2009), os sistemas de pagamento podem ser projetados para atingir um grande número de objetivos. Alguns deles são: melhorar a produtividade e a satisfação do cliente, controlar custos, tratar os empregados com justiça, atender às exigências legais e aperfeiçoar o desempenho individual ou coletivo.

Bohlander e Snell (2009) informam que as bases nas quais a remuneração é determinada e a forma como são administradas podem afetar significativamente a produtividade dos funcionários e a realização dos objetivos de uma organização.

\section{Os subsistemas de recursos humanos e a gestão por competência}

Esta seção expõe sucintamente a abordagem estratégica da gestão de pessoas e apresenta os subsistemas de $\mathrm{RH}$ na roupagem da gestão por competências. 
De acordo com Dutra et al. (2010), a gestão por competência tem sido um dos temas mais usualmente tratados por estudiosos, consultores, empresários e governo nesses últimos anos. O termo "competência" aponta para uma grande variedade de abordagens e compreensões distintas sobre seu conceito e aplicabilidade, gerando uma abordagem estratégica para a gestão de pessoas.

Após análise de dozeartigos dirigidos para osubtema "competências organizacionais", de acordo com Dutra et al. (2010), observou-se que a vinculação das competências com a estratégia compreende duas grandes interações. A primeira é a interação estratégica, que trata da adaptação e definição do conjunto de competências organizacionais à estratégia, a fim de sustentá-las. A segunda é a interação operacional entre as competências organizacionais definidas como estratégicas e as competências de grupos e pessoas nas atividades operacionais da empresa.

O primeiro eixo tem sido considerado altamente importante para o desenvolvimento de competitividade, pois defende a ideia de que os recursos internos da empresa constituem seus principais fatores de competição. Dutra et al. (2010) informam que essa dimensão consiste no processo de priorizar e desenvolver competências no nível das diferentes áreas da empresa (comercial, produção, pesquisa e desenvolvimento, administrativo e financeiro) que vão concretamente sustentar as diretrizes e projetos estratégicos.

O autor, sinteticamente, expõe competência na sua dimensão estratégica, enfocando o conceito de competência organizacional como referência e priorização da gestão do desenvolvimento de capacidades que devem sustentar a competitividade empresarial.

O outro eixo conceitual coaduna com as próprias práticas de gestão de pessoas. Segundo Dutra et al. (2010), a competência, quando focada predominantemente no desempenho, na mobilização contextualizada e na contribuição do trabalho para a estratégia da empresa, constitui um importante instrumento de referência para as diferentes responsabilidades e contribuições individuais dentro da 
empresa. Com esse foco, a administração de empresas deve procurar e encontrar novas referências para tratamento e gestão do trabalho que sejam compatíveis com o novo ambiente - é aí que se encontra o conceito de competência.

A consolidação da noção de competência começa pela mudança do conceito de qualificação para o de competência. Ou seja, a ênfase passa a ser a identificação das capacidades necessárias para realizar tipos determinados de tarefas e obter um desempenho superior. Isso ocorre em meados da década de 1980, segundo Dutra et al. (2010).

De forma geral, as perspectivas dos autores mostram-se distintas, podendo centrar-se em aspectos voltados para o treinamento, compreendendo a formação, o comportamento e os resultados desejados, ou aspectos de desempenho, incluindo aptidão, autodesenvolvimento e formas de ação. Ressalta-se que a heterogeneidade do conceito abordado não deve dificultar a construção da pesquisa.

\subsection{Subsistema de recrutamento e seleção por competência}

A gestão por competência evidencia que a captação de pessoas adequadas às necessidades da organização exige a definição dos seguintes aspectos: perfil profissional e comportamental, definição das entregas desejadas para atender às necessidades presentes e futuras da organização, definição das condições contratuais ou vínculos empregatícios e do desenvolvimento profissional (DUTRA et al., 2010).

De acordo com Dutra (2010), o estabelecimento do perfil adequado da pessoa a ser captada é um aspecto fundamental da estratégia de gestão de pessoas, uma vez que, admitida, ela será parte da organização por tempo indeterminado. Além disso, de acordo com o autor, obtêm-se uma visão dinâmica do movimento ou trajetória dessa pessoa ao entrar na organização.

Dutra (2010) esclarece que o foco na trajetória é o aspecto mais marcante da diferença entre a abordagem tradicional e a abordagem por competência na movimentação de pessoas. Ele expõe no Quadro 
1 um resumo das principais diferenças entre a abordagem tradicional e a abordagem por competência no recrutamento e seleção de pessoas.

Quadro 1 - Diferentes abordagens para a captação de pessoas Fonte: Dutra (2010).

\begin{tabular}{|l|l|l|}
\hline $\begin{array}{l}\text { ASPECTOS } \\
\text { ANALISADOS }\end{array}$ & \multicolumn{1}{|c|}{$\begin{array}{c}\text { ABORDAGEM } \\
\text { TRADICIONAL }\end{array}$} & \multicolumn{1}{c|}{$\begin{array}{c}\text { ABORDAGEM } \\
\text { POR COMPETÉNCIA }\end{array}$} \\
\hline $\begin{array}{l}\text { Horizonte } \\
\text { profissional }\end{array}$ & Cargo a ser ocupado & $\begin{array}{l}\text { Carreira da pessoa na } \\
\text { empresa }\end{array}$ \\
\hline Perfil & Para um cargo específico & $\begin{array}{l}\text { Para atender a demandas } \\
\text { presentes e futuras }\end{array}$ \\
\hline $\begin{array}{l}\text { Processo de } \\
\text { escolha }\end{array}$ & $\begin{array}{l}\text { Observa a adequação } \\
\text { para o cargo }\end{array}$ & $\begin{array}{l}\text { Observa a adequação para } \\
\text { uma trajetória específica }\end{array}$ \\
\hline $\begin{array}{l}\text { Ferramentas de } \\
\text { escolha }\end{array}$ & $\begin{array}{l}\text { Testes de conhecimentos, } \\
\text { habilidades e atitudes } \\
\text { necessárias para o cargo }\end{array}$ & $\begin{array}{l}\text { Análise da trajetória } \\
\text { profissional para avaliar a } \\
\text { maturidade profissional e o } \\
\text { ritmo de desenvolvimento }\end{array}$ \\
\hline $\begin{array}{l}\text { Contrato } \\
\text { psicológico }\end{array}$ & $\begin{array}{l}\text { Contrato construído } \\
\text { visando determinada } \\
\text { posição na empresa }\end{array}$ & $\begin{array}{l}\text { Contrato construído visando } \\
\text { uma carreira ou trajetória } \\
\text { profissional na empresa }\end{array}$ \\
\hline $\begin{array}{l}\text { Compromisso } \\
\text { da organização }\end{array}$ & $\begin{array}{l}\text { Manter o cargo para o } \\
\text { qual a pessoa está sendo } \\
\text { captada }\end{array}$ & $\begin{array}{l}\text { Desenvolver a pessoa } \\
\text { para determinada trajetória } \\
\text { dentro da empresa }\end{array}$ \\
\hline Internalização & Adequação ao cargo & Adequação a uma trajetória \\
\hline
\end{tabular}

\subsection{Subsistema de treinamento e desenvolvimento por competência}

O treinamento e o desenvolvimento são essenciais para os profissionais dentro da organização. Assim sendo, dentro da abordagem da gestão por competência, Dutra (2010, p. 65) definiu desenvolvimento profissional da pessoa como "capacidade para assumir atribuições e responsabilidades em níveis crescentes de complexidade”.

O autor acrescenta que o uso da abordagem por competência no desenvolvimento das pessoas possibilita o surgimento das bases para conciliar as expectativas das pessoas e da organização. É possível estabelecer com maior nitidez o papel da pessoa na gestão de seu desenvolvimento e de sua carreira e o papel da empresa no suporte ao 
desenvolvimento da pessoa, pois esta não é olhada exclusivamente em função do cargo que ocupa, e sim de sua trajetória.

Esse ângulo de visão proporcionado pela gestão por competência permite à pessoa enxergar um horizonte mais extenso do que o cargo que ela ocupa, ao mesmo tempo em que esse horizonte também fica mais claro para a empresa em relação à sua perspectiva de retorno em longo prazo.

Dutra (2010) evidencia que o uso da abordagem por competência possibilita construir um sistema de gestão do desenvolvimento que busca analisar a individualidade e as deficiências da pessoa, permitindo uma melhor adequação das ações de treinamento e desenvolvimento. Tais ações devem ser definidas com base nas necessidades de cada pessoa em particular e na premissa de ajudá-la a mobilizar seus pontos fortes para desenvolver-se.

\subsection{Subsistema de avaliação de desempenho por competência}

Na gestão de pessoas, um dos pontos mais difíceis é definir e avaliar o que é desempenho. Na gestão por competência, Dutra (2010, p. 69) define desempenho como "conjunto de entregas e resultados de determinada pessoa para a empresa ou o negócio". Para o autor, o desempenho de uma pessoa divide-se em três dimensões que interagem entre si: desenvolvimento, esforço e comportamento.

Dutra (2010) expõe que, geralmente, as empresas mesclam as três dimensões e acabam dando mais ênfase ao esforço e ao comportamento. As empresas que enfatizam essas duas dimensões estão mais orientadas para o curto prazo. Já as empresas que estimulam as pessoas para o desenvolvimento estão orientadas para o médio e o longo prazo. Atualmente, com o uso da abordagem por competência, o desenvolvimento é a dimensão mais importante do desempenho e deve receber atenção diferenciada. Sem essa abordagem, dificilmente o desenvolvimento seria percebido de forma concreta, passível de mensuração. 


\subsection{Subsistema de remuneração ou cargos e salários por competência}

Para Dutra (2010), embasado na gestão por competência, a remuneração das pessoas é relacionada aos diferentes patamares de complexidade da carreira, ou seja, pode-se associar uma faixa salarial para cada degrau de complexidade. Desse modo, independentemente de como a empresa organize a questão da remuneração, há uma regra intrínseca: na medida em que a pessoa se desenvolve, aumenta sua agregação de valor e ela passa a valer mais para a empresa e para o mercado.

De acordo com o autor, a remuneração obedece à lógica da agregação de valor da pessoa, embora os sistemas formais da empresa estejam baseados em cargos e, por decorrência, nas tarefas, atividades ou funções executadas por pessoas. O problema da abordagem que utilizar cargo como referência é, segundo o autor, que ela se apoia em uma base instável, pois o cargo não continua igual no tempo, ou seja, as tarefas e as responsabilidades das pessoas estão em constante alteração. Portanto, é necessário um padrão estável no tempo e, para a abordagem por competência, esse padrão é a complexidade das entregas esperadas da pessoa. Mesmo que essas entregas mudem no tempo, o que importa é o grau de sua complexidade. O grau é estável no tempo e pode ser transformado em uma base métrica sólida.

Dutra (2010) ressalta que a remuneração não deve estar atrelada à competência, e sim à complexidade. A articulação entre os conceitos de competência, complexidade e espaço ocupacional permite uma visão ampla e integrada para esse subsistema, dentro da abordagem estratégica da gestão de pessoas.

\section{A gestão de pessoas por competência no setor público}

Considerando o enfoque deste trabalho direcionado ao setor público, faz-se necessário abordar a gestão de pessoas nesse contexto. De acordo com Pires et al. (2005), o setor público enfrenta dois 
importantes desafios para a política de gestão de recursos humanos: a construção de mecanismos efetivos de motivação dos servidores e o alinhamento das atividades de gestão de pessoas às estratégias das organizações e às diretrizes gerais estabelecidas pelos governos.

Diante do cenário desafiador para as instituições públicas, as políticas de gestão de recursos humanos buscam novos conceitos espelhados na iniciativa privada, chegando, assim, à abordagem de gestão por competência.

Em 23 de fevereiro de 2006, o Governo Federal publicou o Decreto $N^{\circ} 5.707$, que institui a política e as diretrizes para o desenvolvimento de pessoal da administração pública federal direta, autárquica e fundacional, e regulamenta dispositivos da Lei $n^{\circ}$ 8.112, de 11 de dezembro de 1990. Após a publicação do referido Decreto, a gestão por competências tornou-se referencial para a gestão de pessoas do setor público federal (BRASIL, 2006).

Para um melhor entendimento sobre gestão por competência no setor público, buscou-se o conceito ditado pelo decreto $N^{\circ} 5.707$ :

Art. $2^{\circ}$ Para os fins deste Decreto, entende-se por:

II - gestão por competência: gestão da capacitação orientada para o desenvolvimento do conjunto de conhecimentos, habilidades e atitudes necessárias ao desempenho das funções dos servidores, visando ao alcance dos objetivos da instituição. (BRASIL, 2006, p. 1)

Para Souza (2004), na Secretaria de Gestão do Ministério do Planejamento, Orçamento e Gestão, esfera competente por articular ações de capacitação gerencial e fomentar o desenvolvimento de pessoas no setor público, nesse âmbito, acredita-se que as diversas atividades que compõem a gestão de pessoas (seleção, desenvolvimento, gestão do desempenho, carreira e remuneração) serão dinamizadas através do modelo de gestão por competência a ser implementado na administração pública, consolidando essa tendência na gestão dos servidores públicos nos próximos anos. 
Para compor este trabalho, dentro da abordagem da gestão por competência, analisaremos os subsistemas de gestão de recursos humanos no setor público.

\subsection{Subsistema de recrutamento e seleção por competência}

No setor público, os processos seletivos externos são caracterizados pela realização de concursos públicos para o preenchimento de cargos. Os principais instrumentos utilizados na realização desses concursos são a aplicação de provas e a comprovação de titulação. As provas abrangem conteúdos amplos, que exigem dos candidatos um elevado nível de conhecimentos para serem aprovados e classificados de acordo com o número de vagas previamente fixado. A exigência da prova de títulos, prevista na legislação, reforça a dimensão acadêmica e cognitiva dos processos de seleção.

Assim sendo, de acordo com Pires et al. (2005), a legislação vigente prioriza o nível de conhecimentos e habilidades dos candidatos, desconsiderando os aspectos relacionados a atitudes, conduta pessoal e interpessoal, valores, posturas, imagem ou percepção que projetam de si, motivação e outros traços de personalidade dos futuros servidores.

A justificativa mais frequente para manter os padrões de seleção atualmente utilizados gira em torno das grandes dificuldades na definição de critérios objetivos para a avaliação desses elementos. A consequência imediata, segundo o autor, é que a seleção pública, tal como é realizada hoje, seleciona candidatos bastante capazes intelectualmente, porém, esses novos servidores não apresentam o perfil adequado para um bom desempenho num cargo ou numa função, o que pode acarretar problemas de adaptação no trabalho, baixa produtividade e altos índices de doenças profissionais decorrentes das falhas no processo seletivo.

É válido resgatar que outra falha desse modelo de seleção no setor público encontra-se no recrutamento. Este, para o setor público, consiste na fase em que se faz a divulgação da vaga, objetivando atrair os candidatos. Ela ocorre através da publicação do edital, o qual passa a 
representar apenas uma exigência formal, quando, na realidade, deveria ter como foco a identificação do perfil desejado dos futuros servidores.

Segundo Pires et al. (2005), o emprego da abordagem das competências em instituições de governo mostra-se ainda relativamente restrito. Nota-se que tal abordagem encontra dificuldades de implementação no setor público, percebível já no primeiro subsistema de $\mathrm{ARH}$, o de recrutamento e seleção. Para contornar essas dificuldades, o autor informa que várias organizações têm optado pela incorporação de mais uma etapa nos concursos públicos: a realização de cursos de formação.

O autor enfatiza que certas habilidades e atitudes somente poderão ser avaliadas após um período de contato que permita o reconhecimento de potencialidades, qualificações e outros aspectos relacionados ao comportamento dos candidatos. Tal fase poderia, estrategicamente, orientar a lotação futura do servidor.

É válido ressaltar que, segundo o autor, no setor público, o processo seletivo desdobra-se durante o período de estágio probatório, mas este, frequentemente, não é corretamente aplicado e acaba por confirmar a nomeação de servidores cujas atitudes e comportamentos deixam a desejar.

Em síntese, os concursos públicos devem ter como objetivo a seleção de indivíduos que apresentem as competências requeridas pelas equipes/áreas a serem supridas. Para esse fim, além da seleção mediante aplicação de provas e comprovação de títulos, outras formas de avaliação devem ser incluídas para aproximar-se das práticas de gestão por competência, porém, zelando pelo caráter público e pela lisura dos processos seletivos.

Pires et al. (2005) destacam que a necessidade de prezar pela manutenção do caráter público dos processos seletivos desde as primeiras etapas de sua realização, como a publicação do edital do concurso, pode ser o motivo de ainda se observar uma atitude de prudência por parte dos gestores e técnicos de recursos humanos do 
setor público. Talvez seja essa a razão pela qual ainda são insignificantes as medidas utilizadas com o objetivo de aferir competências na seleção de talentos no mercado externo às instituições públicas.

\subsection{Subsistema de treinamento e desenvolvimento por competência}

De acordo com Pires et al. (2005), as competências estabelecidas em função do cargo ou da posição ocupada pelo indivíduo na organização remetem não apenas aos saberes cognitivos e técnicos, mas também à capacidade de os servidores solucionarem problemas, lidarem com situações inesperadas, compartilharem e transferirem conhecimentos que consistem, de acordo com o autor, nos saberes em ação.

As atividades de desenvolvimento de competências na administração pública, assim como na iniciativa privada, podem auxiliar o planejamento das carreiras. De acordo com o autor, para cada classe ou padrão de uma carreira, pode ser definido um conjunto de conhecimentos, habilidades e atitudes segundo uma escala de complexidade, com o objetivo de ampliar o acesso às variáveis cognitivas e comportamentais que melhorem o desempenho individual em cada nível e, consequentemente, a qualidade da entrega organizacional. Desse modo, tanto a instituição como o servidor podem conhecer o nível inicial de competências e definir o plano de desenvolvimento necessário à progressão funcional e à promoção.

Pires et al. (2005) esclarecem que, baseado no desvio entre as competências apresentadas pelo servidor e as requeridas para o alcance das metas organizacionais, o plano de desenvolvimento de competências objetiva: aumentar a capacidade individual para assumir atribuições e responsabilidades em níveis crescentes de complexidade, indicar os pontos fortes e fracos, apresentar as carências individuais para o desenvolvimento profissional, estruturar um plano de capacitação para reduzir o hiato de competências e estimular o aprendizado contínuo e o autodesenvolvimento. 
O plano de desenvolvimento, de acordo com o autor, pode abranger desde treinamentos estruturados, como cursos, ciclos de palestras e seminários, até visitas técnicas a organizações nacionais ou internacionais, estágios, grupos de trabalho e etapas de autoaprendizado.

É válido ressaltar que o desenvolvimento de competências profissionais, que deve ter como objetivo a mudança do indivíduo, só poderá alcançar os efeitos esperados se o contexto e o ambiente organizacional favorecem a adoção dessa nova visão sobre a gestão de pessoas.

\subsection{Subsistema de avaliação de desempenho por competência}

Para Oliveira-Castro, Lima e Veiga (1996 apud PIRES et al., 2005, p. 39), a avaliação de desempenho é definida como "um conjunto de normas e procedimentos utilizados pelas organizações para aferir o nível de produtividade de seus empregados". De acordo com os autores, diferentes fatores nos contextos extraorganizacional e intraorganizacional, no ambiente de tarefas e nas próprias características do trabalhador afetam o desempenho no trabalho.

Pires et al. (2005) ressaltam que, no setor público, sob a ótica da nova legislação, a avaliação de desempenho individual busca aferir a atuação do servidor no exercício das atribuições do cargo ou da função, focalizando a contribuição individual para o alcance dos objetivos organizacionais. A pontuação obtida pelo funcionário está relacionada ao índice de alcance das metas de desempenho institucional estabelecidas pelo órgão, bem como aos procedimentos e critérios específicos para a atribuição da gratificação.

O autor informa que, na avaliação do desempenho individual, deverão ser estabelecidos: os fatores a serem aferidos, os indicadores de desempenho, o peso relativo de cada fator, a metodologia a ser utilizada e os mecanismos para encaminhamento de recursos por parte do servidor avaliado (ENAP, 2003).

No momento em que se definem claramente quais os padrões de desempenho a serem atingidos pelo servidor, partindo da análise das 
competências, estabelece-se um plano de desenvolvimento individual que fornece um feedback sobre o seu desempenho e, consequentemente, proporciona-se um novo significado à sua atuação.

Segundo Pires et al. (2005), vários fatores não medem o desempenho no trabalho, além de terem como foco preferencial aspectos subjetivos da atividade laboral. Nas últimas décadas, de acordo com o autor, observa-se uma evolução na definição dos fatores de avaliação, pois os estabelecidos pela legislação mais recente incidem diretamente na atuação efetiva do servidor no ambiente de trabalho.

Acredita-se que, com a abordagem da gestão por competências, pode-se contribuir para a reestruturação dos processos de gestão do desempenho, resgatando a sua importância e dando maior qualidade ao trabalho do servidor público. Para Pires et al. (2005), é sobretudo nas organizações públicas que se pode resgatar essa perspectiva de valorização do trabalho, visto que, em tais organizações, a ampliação dos níveis de lucratividade não é, em geral, o objetivo de maior importância.

\subsection{Subsistema de remuneração ou cargos e salários por competência}

De acordo com Pires et al. (2005), na administração pública, o tempo de serviço tem sido a variável mais importante para a determinação da evolução das carreiras dos servidores nos cargos. Para ele, não há, entre os servidores de um mesmo cargo e/ou carreira, grande variação salarial em decorrência de variáveis como desempenho, qualificação, compartilhamento de conhecimentos ou produção de resultados.

Segundo o autor, a atual estrutura de remuneração é constituída, de forma geral, por uma parcela fixa, hierarquicamente estruturada em classes e em treze padrões, e por uma parcela variável, correspondente a uma gratificação de desempenho individual e institucional sujeita a obedecer a uma "curva forçada", o que não permite uma justa avaliação do desempenho do servidor. 
A noção de "curva forçada" é utilizada com frequência para indicar a existência, na legislação vigente, de regras que obrigam os gestores públicos a obedecer ao padrão de remuneração estabelecido por uma curva normal previamente fixada.

Além desse padrão a ser seguido, os planos tradicionais de cargos e carreiras do setor público são caracterizados, principalmente, pela falta de flexibilidade, objetividade e visão de futuro, o que não contribui para o aperfeiçoamento das práticas de recursos humanos dessas organizações.

Para Souza (2004), o pressuposto de um mundo estável e previsível reduz os sistemas de remuneração dos servidores públicos a um mecanismo para medir a contribuição dos profissionais, concentrada apenas nas atividades requeridas pelo cargo, para, assim, definir sua remuneração. Esse parâmetro, utilizado na administração pública, ficou inadequado com as inúmeras mudanças ocorridas que romperam com as tradicionais práticas de gestão de pessoas.

Segundo Pires et al. (2005), para que os atuais planos de cargos e carreiras dos servidores públicos sejam adequados ao novo modelo de remuneração por competências, serão necessárias as seguintes mudanças: alinhá-los às estratégias da instituição, torná-los orientados a resultados e, principalmente, torná-los capazes de incentivar práticas participativas e o desenvolvimento continuado das pessoas.

Pode-se inferir, através da visão dos autores, que a principal causa da desmotivação de muitos servidores no serviço público seja a ausência de uma política de reconhecimento e de remuneração com base nas competências efetivamente adquiridas, consolidando-se como um desafio para a gestão de pessoas ajustar o modelo de remuneração atual ao proposto pela gestão por competência.

Nesse contexto, Pires etal. (2005) esclarecem que a nomeação para cargos de confiança cumpre a função de viabilizar o reconhecimento de servidores que se destacam pelo seu desempenho. Porém, a nomeação também é codeterminada pelas "relações de confiança", portanto, 
sofre a influência de fatores relacionais e políticos em detrimento da consideração das competências demonstradas.

Para o autor, a progressão dos servidores e a definição dos seus respectivos níveis de remuneração devem refletir as avaliações de competências e de resultados do funcionário, aferidas pela avaliação de desempenho. Sendo a avaliação de desempenho o somatório das competências entregues com os resultados produzidos, ela deve ser considerada quesito fundamental na determinação da progressão na carreira e, consequentemente, na remuneração variável do servidor.

Segundo Pires et al. (2005), a adoção do modelo de gestão por competências resulta em menor peso do critério "relação de confiança" e aumento do peso do critério "competências adequadas" para a investidura no cargo. A superação do conceito de "cargo de confiança" e a afirmação do conceito de "cargo de competência" passam a ser uma mudança bastante significativa para o setor público.

Essa mudança é essencial para proporcionar um salto de qualidade em aproveitamento do potencial humano no setor público. Assim, segundo o autor, tende-se a reduzir a importância de fatores como afinidade, compatibilidade entre personalidades, padrões de comportamento e vinculação pessoal, que são os principais determinantes das "relações de confiança".

Segundo o autor, adotar a abordagem por competência para reestruturar os sistemas de cargos, carreiras e remuneração no serviço público pode levar aos seguintes resultados: clareza na definição dos prérequisitos ou competências necessárias para a progressão na carreira; criação de critérios baseados em competências para o exercício de cargos de confiança; desenvolvimento de sistemática de comparação e avaliação do sistema de remuneração e reconhecimento da organização em relação ao praticado pelo mercado público e privado, nacional e internacional; desenvolvimento de sistemática de remuneração vinculada ao aprimoramento e reconhecimento de competências que são determinantes para a melhoria do desempenho da organização; e desenvolvimento de banco de talentos que permita a identificação e 
formação dos potenciais sucessores para os cargos gerenciais e críticos da organização (PIRES et al., 2005).

\section{Metodologia da pesquisa}

\subsection{Perfil da organização}

O estudo de caso proposto foi realizado na Universidade Federal do Ceará (UFC), especificamente, na Superintendência de Recursos Humanos (SRH). À SRH compete supervisionar, coordenar, gerir e controlar as atividades relacionadas com administração e desenvolvimento de pessoal, assistência ao servidor, legislação, registros funcionais, inquéritos administrativos, acumulação de cargos, avaliação ambiental e perícia para a concessão de adicionais no âmbito da UFC.

De acordo com informações disponibilizadas pelo serviço de acesso à informação, protocolo n 23480.013553/2012-14, a SRH conta oficialmente com 156 servidores, distribuídos nas diversas categorias (A, B, C, D e E). Em abril de 2012, mês da aplicação do questionário, de acordo com informações fornecidas pelo referido protocolo, 7 servidores estavam de férias, 1 afastado para estudo ou missão no exterior, 1 disponível a júri, 1 encontrava-se em licença gestante, 8 em licença para tratamento de saúde e 15 cedidos, reduzindo o tamanho do universo para um total de 124 servidores.

\subsection{Tipo de pesquisa}

Para a realização desta pesquisa exploratória, foi utilizado o estudo de caso. As pesquisas classificadas como exploratórias, de acordo com Gil (2010), proporcionam maior familiaridade com o problema, tornando-o mais explícito. A utilização do estudo de caso justifica-se, segundo Yin (2001 apud Gil, 2009), por este ser encarado como o delineamento mais adequado para a investigação de um fenômeno contemporâneo dentro de um contexto real, no qual os limites entre o fenômeno e o contexto não são percebidos claramente. 
As pesquisas bibliográficas e de campo justificam-se na medida em que contribuíram para a identificação do alinhamento ou das possíveis divergências existentes e possibilitaram a realização de um estudo comparativo entre a teoria sobre administração de recursos humanos tradicional e a abordagem estratégica de recursos humanos, ou seja, a gestão por competência dentro de uma instituição pública.

O universo da pesquisa compreende toda a $\mathrm{SRH}$, contendo um total de 124 servidores efetivamente ativos em abril de 2012. A amostra utilizada foi a não probabilística por acessibilidade ou por conveniência. A natureza da pesquisa exploratória permite a flexibilidade necessária para esse tipo de amostragem, em que "o pesquisador seleciona os elementos a que tem acesso, admitindo que estes possam de alguma forma, representar o universo" (GIL, 2007, p. 104).

Foram distribuídos os questionários, de forma presencial, em todos os setores da SRH. O início da distribuição deu-se em 9 de abril de 2012, disponibilizando em cada setor o número de questionários para os servidores presentes e ausentes. A distribuição e recolhimento se estenderam até o dia 27 de abril de 2012. O recolhimento deu-se principalmente em blocos devolvidos por cada setor, impossibilitando a identificação do servidor e garantindo total preservação da sua identidade e maior credibilidade aos dados coletados na pesquisa. Foi distribuído um total de 76 questionários e foram recolhidos 53 . Em relação ao universo, obteve-se uma amostra de $42,74 \%$ dos servidores lotados na SRH.

O método escolhido para o estudo apresenta limitações, sendo a principal a abrangência. A pesquisa abordou apenas os servidores técnico-administrativos concursados lotados na SRH que se dispuseram a responder ao questionário; assim, é possível que os servidores que participaram da pesquisa não sejam os mais representativos para o universo estudado, mas esse é um risco de qualquer processo de investigação. 


\subsubsection{Ferramenta de pesquisa}

O questionário utilizado como principal ferramenta para a coleta de dados primários desta pesquisa foi elaborado com questões objetivas, para permitir um melhor tratamento dos dados quantitativos e uma seção com questões subjetivas, visando à obtenção e análise de dados qualitativos.

O questionário é subdividido em seis seções: I. Dados do respondente; II. Subsistema de recrutamento e seleção; III. Subsistema de treinamento e desenvolvimento; IV. Subsistema de avaliação de desempenho; V. Subsistema de remuneração; e VI. Disponibilização de espaço para críticas, sugestões ou elogios para cada uma das funções de gestão de pessoas na UFC.

Da segunda até a quinta seção, há itens relacionados à análise objetiva dos quatro subsistemas de gestão de recursos humanos na UFC. Cada seção aborda um subsistema por meio de quatro afirmativas. O servidor deveria realizar uma escolha, obedecendo a uma legenda em formato de escala do tipo Likert, a partir de cinco opções: CT - Concordo Totalmente; CP - Concordo Parcialmente; DP - Discordo Parcialmente; DT - Discordo Totalmente; NS - Não Sei Responder.

Ao final do questionário, encontra-se a sexta seção, na qual é disponibilizado aos respondentes um espaço em branco para críticas, sugestões ou elogios a cada uma das funções de gestão de pessoas analisadas anteriormente, concluindo-se com um agradecimento à colaboração do participante na pesquisa.

A realização da pesquisa possibilitou identificar se os subsistemas de administração de recursos humanos, na percepção dos servidores da SRH, estão alinhados às diretrizes propostas pela gestão por competência.

\section{Análise e apresentação dos resultados}

O tratamento dos dados foi feito em planilha eletrônica no sistema operacional Windows, utilizando o programa Excel. A análise dos 
questionários foi iniciada pelos dados referentes ao perfil do respondente, obtidos da primeira seção do questionário.

\subsection{Síntese dos resultados sobre o perfil dos respondentes}

A pesquisa identificou participação de todas as categorias de servidores, sendo a maior parte, 46,94\% ( $n=23)$, na categoria $D$, seguida da categoria $E$, com $36,73 \%(n=18)$.

Quanto à formação, a maioria dos servidores respondentes, $42,31 \%$ ( $n=22$ ), encontra-se no nível lato sensu, com curso de especialização, e a segunda maioria, 26,92\% ( $n=14)$, apresenta curso superior completo. A área de formação dos servidores respondentes apresenta-se bastante diversificada: 53,06\% $(n=26)$ dos respondentes enquadram-se em área de formação diversa da proposta pela pesquisa; dentre as citadas estão: educação, educação física, engenharia civil, engenharia mecânica, filosofia, história, informática, letras, medicina, pedagogia, processamento de dados, secretariado executivo, serviço social, sociologia. A segunda maioria de respondentes, $26,53 \%(n=13)$, concentra-se na área da administração.

Quanto ao departamento de lotação dos servidores analisados, a maior parte dos respondentes pertence ao Departamento de Administração de Pessoal (DAP), representado por 45,28\% ( $n=24)$. Em seguida, o Departamento de Desenvolvimento Profissional (DDP), com $30,19 \%(n=16)$ dos respondentes. $E$, finalizando, o Departamento de Desenvolvimento Humano (DDH), com 24,53\% ( $n=13)$.

Quanto ao sexo, há uma inconsistência nos números, decorrente da abstenção a esse questionamento. Acredita-se que, pelo posicionamento lateral da questão, o respondente pode não ter observado sua existência no questionário, ficando uma distribuição de 60,53\% ( $n=23)$ pertencentes ao sexo feminino e $39,47 \%(n=15)$, ao sexo masculino. Ressalta-se que nem todos os participantes responderam a esse questionamento, mas esse dado não prejudica a pesquisa. 
O último quesito analisado para a caracterização do servidor foi o tempo de serviço. As respostas concentraram-se basicamente em dois blocos: o primeiro com 55,77\% $(n=29)$ dos servidores com tempo de serviço na UFC acima de quinze anos e o segundo maior bloco com $19,23 \%(n=10)$ dos servidores no início de carreira, de zero a três anos de trabalho na UFC.

\subsection{Resultados da avaliação do subsistema de recrutamento e seleção}

A segunda seção inicia a obtenção dos dados específicos da pesquisa sobre os atuais subsistemas de gestão de pessoas na UFC e sua interação com a gestão por competência. O primeiro subsistema abordado foi o de recrutamento e seleção (R\&S). Tal subsistema foi explorado através de quatro questionamentos, os quais serão tratados individualmente.

O primeiro questionamento, item 2.1, indaga ao respondente se o edital do concurso público para técnico-administrativo apresentava claramente as competências exigidas pelo cargo. Observando o Gráfico 1 , percebe-se que houve uma concordância parcial na resposta de 33,96\% $(n=18)$ dos servidores. O mesmo percentual concorda totalmente que as competências exigidas pelo cargo estavam apresentadas no edital do concurso.

O item 2.2 é referente à prova realizada no processo seletivo. A afirmativa questiona ao respondente se a prova escrita realizada permite avaliar as competências que serão exigidas dos futuros servidores. Esse item obteve resposta bem definida, representada por 52,83\% ( $n=28$ ) dos servidores elegendo a opção "concordo parcialmente". Observe a distribuição dos dados no Gráfico 1.

O item 2.3 questiona se é possível, no atual processo seletivo, a aprovação de um candidato que não possua as competências exigidas para o cargo. A maioria dos respondentes, 35,85\% ( $n=19)$, afirmou que concorda totalmente com a possibilidade, e a resposta é ratificada 
com a segunda e expressiva concordância parcial de 28,30\% ( $n=15)$ dos respondentes. Os referidos percentuais podem ser observados no Gráfico 1.

O item 2.4 reporta-se ao estágio probatório e também está disponível no Gráfico 1. O referido item questiona se o período de estágio probatório é atualmente utilizado de forma eficiente como uma etapa do processo seletivo, possibilitando a comparação das competências apresentadas pelo servidor com as competências exigidas pelo cargo. Os respondentes, em sua maioria, representada por 45,28\% ( $\mathrm{n}=$ $24)$, concordaram parcialmente, seguidos de $37,74 \%(n=20)$ que concordaram totalmente.

Gráfico 1 - Subsistema de recrutamento e seleção

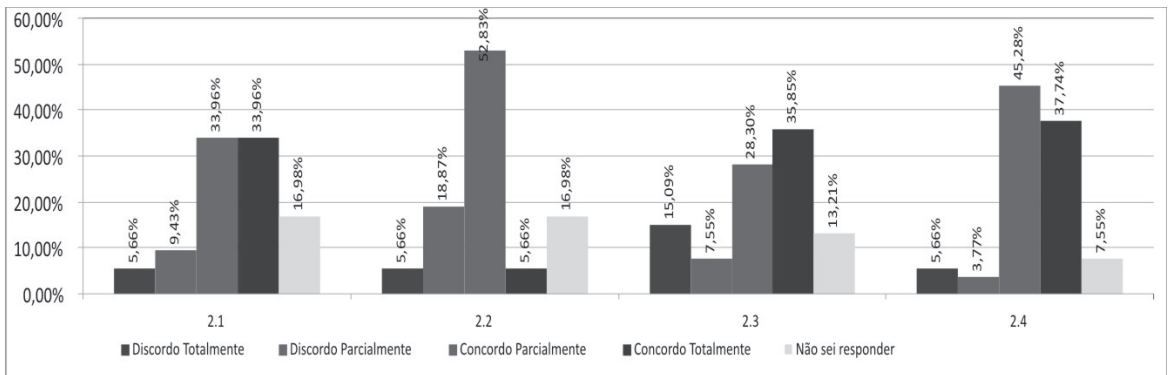

Fonte: elaboração própria.

4.3.2.1 Síntese dos resultados da percepção do servidor sobre o subsistema de recrutamento e seleção e sua interação com a gestão por competência

A pesquisa retratou que o subsistema de recrutamento e seleção (R\&S), na percepção dos servidores técnico-administrativos lotados na $\mathrm{SRH}$, segue as diretrizes propostas pela gestão por competência, expressando nos quatro questionamentos sua concordância parcial ou total. Porém, há algumas divergências entre a teoria sobre a gestão por competência e a percepção do respondente. Na prática, o que se observa no edital para os cargos de técnico-administrativo da UFC são exigências da educação formal, referentes aos conhecimentos técnicos 
do candidato, e, de acordo com a teoria exposta neste trabalho, a gestão por competência requer, além de tais conhecimentos, a avaliação das habilidades e atitudes do indivíduo. Com relação à prova realizada para selecionar os servidores, os respondentes concordaram parcialmente que ela avalia as competências exigidas para o futuro servidor. Com relação à aprovação no processo seletivo, em sua maioria, os respondentes concordaram totalmente que é possível a aprovação de um candidato que não possua as competências exigidas pelo cargo, ficando dissonante com as diretrizes da gestão por competência nesse item; porém, na percepção dos servidores, essa triagem ocorre no período de estágio probatório, tido como uma fase eficiente do processo seletivo.

Em linhas gerais, o subsistema de recrutamento e seleção, na percepção dos respondentes, está alinhado com as diretrizes da gestão por competência. Ressalta-se que a pesquisa retrata a percepção do servidor, mas, de acordo com a teoria, há uma necessidade de aprimorar tal alinhamento.

\subsection{Resultados da avaliação do subsistema de treinamento e desenvolvimento}

O segundo subsistema abordado foi o de treinamento e desenvolvimento (T\&D), também tratado através de quatro questionamentos. O primeiro item, 3.1, faz referência aos cursos de capacitação ofertados aos servidores da UFC e seu impacto no desenvolvimento das competências exigidas pelo cargo. No Gráfico 2, pode-se visualizar que a maioria dos respondentes, 45,28\% ( $n=24)$, concorda parcialmente com o desenvolvimento das competências exigidas pelo cargo através de cursos de capacitação. Em seguida, $33,96 \%(n=18)$ dos respondentes concordaram totalmente que os cursos de capacitação ofertados pela UFC favorecem o desenvolvimento das competências exigidas pelo cargo.

O item 3.2 busca a percepção do servidor sobre os cursos de qualificação. A avaliação dos respondentes foi relativamente a mesma 
do item anterior. O Gráfico 2 apresenta que 39,62\% ( $n=21)$ dos respondentes concordam parcialmente e 33,96\% ( $n=18)$ concordam totalmente que os cursos de qualificação ofertados aos servidores técnico-administrativos favorecem o desenvolvimento das competências exigidas pelo cargo.

O item 3.3 refere-se ao formulário de levantamento das necessidades de treinamento (LNT). O questionamento visa abordar se o referido formulário é utilizado como um instrumento eficaz para identificar as necessidades de capacitação do servidor. A maioria dos respondentes, 39,62\% ( $n=21)$, concorda parcialmente com a utilização eficaz do formulário, porém, $24,53 \%(n=13)$ apontam sua discordância parcial.

O item 3.4 indaga ao respondente se as carências de treinamento, identificadas por meio do formulário de LNT, são plenamente atendidas, de forma a possibilitar ao servidor o desenvolvimento de suas competências. A maioria dos respondentes, representada por 39,62\% (n $=21)$, concordou parcialmente, mas 30,19\% $(n=16)$ expressaram sua discordância parcial.

\section{Gráfico 2 - Subsistema Treinamento e Desenvolvimento}

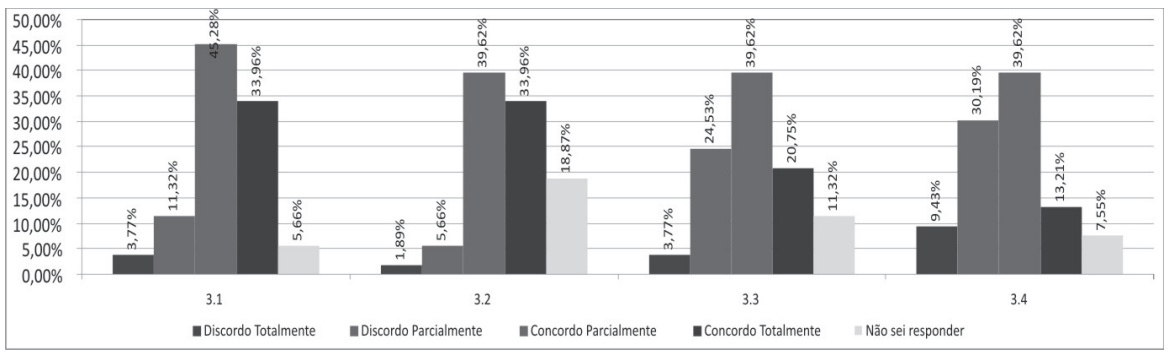

Fonte: elaboração própria. 
4.3.3.1 Síntese dos resultados da percepção do servidor sobre o subsistema de treinamento e desenvolvimento e sua interação com a gestão por competência

Para o subsistema de treinamento e desenvolvimento, a percepção do servidor apresentou, nos questionamentos 3.1 e 3.2, referentes aos cursos de capacitação e qualificação, uma concordância que os alinham às propostas da gestão por competência. Porém, a divergência apresentada nos dois últimos questionamentos, 3.3 e 3.4, referentes à eficácia do formulário de LNT para identificar as necessidades de capacitação e verificar se elas são plenamente atendidas, leva a observar que, nesse subsistema, é necessária uma atuação mais incisiva para adequá-lo às diretrizes propostas pela gestão por competência. Dutra (2010) evidencia que o uso da abordagem por competência possibilita construir um sistema de gestão do desenvolvimento que busca analisar a individualidade e as deficiências da pessoa, permitindo uma melhor adequação das ações de treinamento e desenvolvimento.

\subsection{Resultados da avaliação do subsistema de avaliação de desempenho}

O subsistema de avaliação de desempenho foi o terceiro a ser pesquisado. Seguindo a estrutura metodológica proposta, foram realizados quatro questionamentos. O item 4.1 busca investigar, na percepção do servidor, se o atual sistema de avaliação de desempenho proporciona à instituição uma visão clara sobre o nível de competência dos servidores. De acordo com o Gráfico 3, o maior número de servidores, 49,06\% ( $n=26)$, expressou sua concordância parcial, porém, houve uma paridade entre as respostas "discordo totalmente" e "discordo parcialmente", totalizando $37,74 \%(n=20)$ e expressando uma sutil indefinição na percepção dos servidores com relação a esse item.

O item 4.2 questiona se a avaliação de desempenho atualmente aplicada na UFC, permite identificar as lacunas de competências entre as exigências do cargo e o nível em que se encontra o servidor. Um 
percentual significativo, 47,17\% ( $n=25)$, concorda parcialmente, mas $24,53 \%(n=13)$ dos respondentes discordam parcialmente.

O item 4.3 busca investigar se a avaliação de desempenho possibilita ao servidor conhecer seus pontos fortes e fracos em relação às competências exigidas pelo cargo. O Gráfico 3 demonstra que a maioria dos servidores, representada por 47,17\% ( $n=25)$, concorda parcialmente que é possível o conhecimento de seus pontos fortes e fracos através da avaliação de desempenho. É válido destacar que houve uma paridade no segundo grupo de respondentes, colocando os servidores que discordam parcialmente em número idêntico aos que concordam totalmente: $16,98 \%(n=9)$. Essa paridade pressiona mais ainda a favor da possibilidade de conhecimento dos pontos fortes e fracos do servidor através da avaliação de desempenho.

O item 4.4 busca investigar se a avaliação de desempenho é atualmente aplicada de forma comprometida pelos superiores, podendo ser utilizada como referencial para a definição de planos de treinamento e desenvolvimento para o servidor. A maioria dos servidores, 39,62\% ( $n=$ 21 ), respondeu que concorda parcialmente com essa afirmativa, porém, a segunda maioria dos respondentes, representada por $26,42 \%(n=14)$, discorda parcialmente, reportando a uma sutil indefinição, perceptível na análise do Gráfico 3.

Gráfico 3 - Subsistema de avaliação de desempenho.

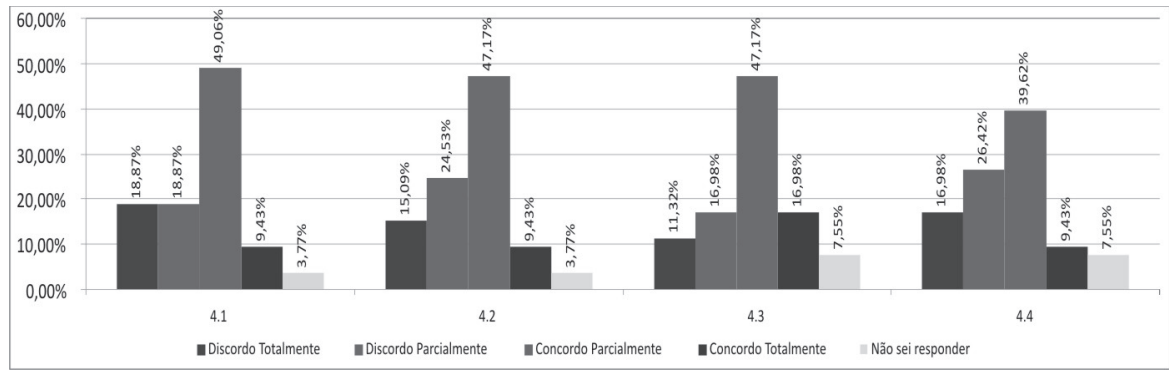

Fonte: elaboração própria. 
4.3.4.1 Síntese dos resultados da percepção do servidor sobre o subsistema de avaliação de desempenho e sua interação com a gestão por competência

O subsistema de avaliação de desempenho foi o que expressou maior indefinição por parte dos respondentes sobre seu alinhamento com a gestão por competência. Quando questionados, no item 4.1, acerca da possibilidade de uma visão clara sobre o nível de competência dos servidores proporcionada pela avaliação de desempenho, a concordância parcial prevaleceu, porém, as significativas parcelas de discordância parcial e total somadas permitem extrair uma sutil indefinição nos respondentes. Assim ocorreu em três dos quatro questionamentos direcionados a esse subsistema. A divergência percebida nas respostas dos servidores indica que é necessária uma melhor utilização desse instrumento de avaliação para alinhá-lo às diretrizes propostas pela gestão por competência, sendo esta, segundo os autores, uma ferramenta valiosa para a implantação deste modelo de gestão.

\subsection{Resultados da avaliação do subsistema de remuneração}

O subsistema de remuneração, também denominado cargos e salários (C\&S), seguiu a mesma metodologia e foi analisado por quatro questionamentos. O item 5.1 buscou investigar a remuneração do servidor, entendendo-a como a adição entre os vencimentos e os benefícios. 0 questionamento indagou se a remuneração ofertada atualmente aos servidores favorece a retenção de profissionais competentes. A maioria dos servidores, 33,96\% ( $n=18)$, discordou totalmente e foi ratificada pela segunda maioria, com 30,19\% ( $n=16)$ discordando parcialmente dessa possibilidade. No Gráfico 4, pode-se perceber que esse item recebeu uma definição clara dos respondentes.

O item 5.2 busca investigar se há um percentual motivador devidamente regulamentado e ofertado aos servidores que assumem função de chefia, as conhecidas funções gratificadas (FG). A maioria expressiva dos servidores, 47,17\% $(n=25)$, respondeu que discorda 
totalmente. O segundo maior grupo, com 22,64\% ( $n=12)$, discorda parcialmente.

O item 5.3 afirma que há um plano de desenvolvimento de carreiras devidamente regulamentado que incentiva o servidor a se desenvolver profissionalmente, assumindo posições crescentes na sua carreira. A maioria dos servidores, 41,51\% $(n=22)$, respondeu que concorda parcialmente. Porém, o Gráfico 4 demonstra que a segunda maioria, 18,87\% ( $n=10)$, discorda parcialmente, seguida de $15,09 \%$ $(n=8)$ dos respondentes que afirmam não saber responder ao referido questionamento. Infere-se uma sutil indecisão para esse item.

O item 5.4 busca indagar ao servidor sua percepção com relação ao Plano de Cargos e Carreiras dos Servidores Técnico-Administrativos em Educação (PCCTAE). O item investiga se o PCCTAE estimula todas as classes de servidores para o desenvolvimento na carreira. No Gráfico 4, a maioria dos respondentes, 45,28\% ( $n=24)$, concorda parcialmente. Houve uma paridade no segundo grupo mais representativo, de modo que a junção dos dois percentuais representa $37,74 \%(n=20)$ dos respondentes que discordam parcial ou totalmente.

Gráfico 4 - Subsistema de remuneração

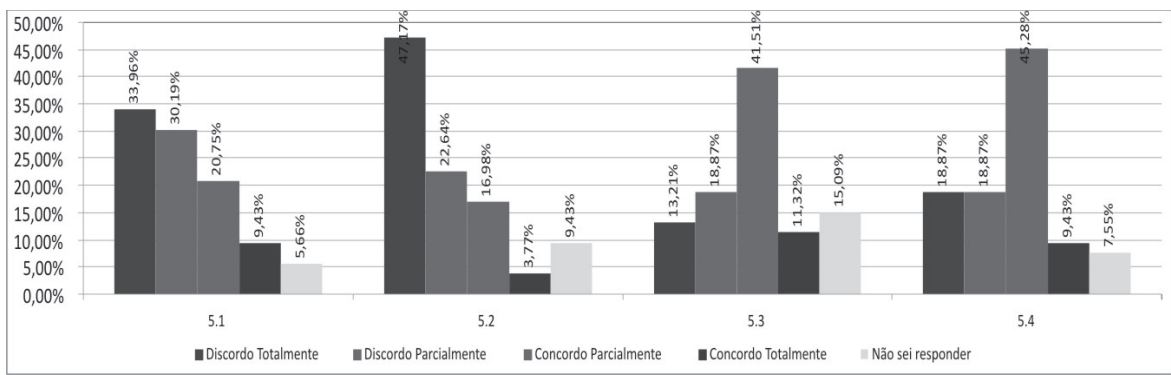

Fonte: elaboração própria. 
4.3.5.1 Síntese dos resultados da percepção do servidor sobre o subsistema de remuneração e sua interação com a gestão por competência

O subsistema de remuneração ou cargos e salários apresentou respostas bem definidas aos dois primeiros questionamentos, 5.1 e 5.2, dos quais os servidores discordaram totalmente, seguido da discordância parcial. Também discordaram totalmente, seguido da discordância parcial, que não há um percentual motivador regulamentado ofertado aos servidores em cargos de chefia, deixando claro que, na percepção do servidor, esse subsistema não está alinhado com as diretrizes propostas pela gestão por competência. Os dois últimos questionamentos, $5.3 \mathrm{e}$ 5.4 , referentes ao plano de desenvolvimento de carreiras e ao PCCTAE, demonstram a indecisão dos respondentes, expressando uma maioria de respondentes concordando parcialmente, seguida de significativas discordâncias parcial e total, além do relevante percentual de respostas "não sei", o que ratifica a fragilidade desse subsistema, atualmente implantado na UFC, diante da ótica do modelo de gestão por competência.

É válido resgatar que, de acordo com os autores, adotar a abordagem por competência para reestruturar os sistemas de cargos, carreiras e remuneração no serviço público pode levar as instituições a alcançarem os seguintes avanços: clareza na definição dos pré-requisitos ou competências necessárias para a progressão na carreira, criação de critérios baseados em competências para o exercício de cargos de confiança e funções gratificadas (FG), desenvolvimento de sistemática de remuneração vinculada ao aprimoramento e reconhecimento de competências que são determinantes para a melhoria do desempenho da organização (PIRES et al., 2005).

\subsection{Síntese dos resultados das críticas, sugestões ou elogios aos subsistemas de gestão de pessoas atualmente implementados na UFC}

Reportando os comentários expostos na seção VI do questionário, em linhas gerais, para o subsistema de recrutamento e seleção (R\&S), os respondentes enfatizaram sua necessidade de melhoria. 
O reconhecimento das dificuldades impostas pela legislação e pelo excessivo número de candidatos que concorrem às vagas para os cargos técnico-administrativos justifica, na visão dos respondentes, a impossibilidade de se promover um processo seletivo mais direcionado ao modelo de gestão por competências.

O subsistema de treinamento e desenvolvimento (T\&D) sofreu algumas críticas direcionadas ao formulário de LNT e aos cursos ofertados, enfatizando que as lacunas de treinamento e dificuldades encontradas pelo servidor na prática de suas atividades e postas no referido formulário não são sanadas pelos cursos ofertados, e que estes, muitas vezes, não têm qualquer impacto sobre as atividades desempenhadas nas unidades. Dessa forma, a percepção do servidor para esse subsistema é de sua subutilização, estando vinculado apenas às necessidades do servidor de melhoria na remuneração decorrentes do cumprimento de carga horária em cursos de natureza genérica ou não direcionados especificamente à sua área de atuação profissional.

A sistemática de aplicação da avaliação de desempenho recebeu elogios, porém, as críticas realizadas a esse subsistema concentram-se em torno do uso meramente simbólico dessa ferramenta, da cultura de descaso na sua aplicação por parte das chefias e da limitação imposta pelos critérios que a compõem, os quais se concentram nas atitudes do servidor, avaliando apenas parte das competências dele requerida.

O subsistema de remuneração ou cargos e salários (C\&S) foi criticado uniformemente por não ser atrativo nem estimulante para o desenvolvimento das carreiras dos servidores. Foram citados os valores irrisórios dos vales-alimentação e das funções gratificadas, indo de encontro às diretrizes propostas pelo modelo de gestão por competência, que utiliza esse subsistema de forma estratégica para incentivar o desenvolvimento simultâneo das carreiras e competências dos profissionais.

É válido destacar que fizeram parte dos comentários as limitações impostas a todos os subsistemas por parte da legislação que rege as 
instituições públicas e a falta de institucionalização do modelo de gestão por competência, estando este em fase de implantação na UFC.

Ressalta-se a relevância de todos os comentários, por serem os respondentes, além de servidores, profissionais que integram o quadro da $\mathrm{SRH}$, o que lhes garante mais competência para fornecer os dados concretos para a pesquisa.

\subsection{Discussão dos resultados}

Dentro do contexto teórico-prático, propõe-se uma discussão dos resultados trazendo as informações originárias dos dados quantitativos e qualitativos da pesquisa e as ideias propostas pelos autores que constituíram a base científica deste trabalho. Será realizada nesta seção, de forma sintética, a interação entre os quatro subsistemas investigados na pesquisa.

Iniciando a análise entre os subsistemas de recrutamento e seleção (R\&S) e o de treinamento e desenvolvimento (T\&D), percebese que, apesar da aprovação de que a UFC possui um subsistema de R\&S voltado às diretrizes da gestão por competência, a presumível falha no R\&S pode ser sanada com T\&D. Tendo em vista que houve concordância parcial nas respostas aos itens investigados em T\&D, o qual visa identificar e desenvolver as competências dos servidores, presume-se o alinhamento desse subsistema às diretrizes da gestão por competência.

A análise entre o subsistema de avaliação de desempenho e o subsistema de R\&S indica que a maioria dos respondentes concorda parcialmente com a possibilidade de essa ferramenta de gestão ser capaz de proporcionar uma visão clara sobre o nível de competência do servidor, bem como identificar as lacunas de competências e os pontos fortes e fracos dele, ratificando a necessária interação entre os subsistemas, sendo a avaliação de desempenho complementar ao R\&S, na medida em que, ainda no estágio probatório, tal avaliação pode identificar as possíveis falhas ocorridas no subsistema de R\&S. 
Analisando R\&S com remuneração ou cargos e salários (C\&S), identifica-se que tal subsistema não está alinhado às diretrizes propostas pela gestão por competência e, consequentemente, presume-se que haja uma rotatividade maior que a esperada para uma instituição pública, o que impacta no subsistema de R\&S, tornando-o bem mais ativo.

Confrontando os resultados quantitativos dos subsistemas T\&D e a avaliação de desempenho, a maioria dos respondentes concordou parcialmente com as afirmativas propostas indicando o alinhamento de ambos às diretrizes propostas pela gestão por competência. É válido ressaltar que, em dados qualitativos, houve críticas à avaliação de desempenho quanto à sua utilização, sendo caracterizada como mero instrumento simbólico, e o subsistema de T\&D também recebeu críticas, por não favorecer o desenvolvimento das competências do servidor, tendo os cursos de capacitação ofertados direcionamentos genéricos, não específicos e incapazes de impactar nas atividades do servidor. No embasamento teórico deste trabalho, foi evidenciada a estreita correlação entre os referidos subsistemas, permitindo considerar, na visão dos autores, o caráter de complementaridade e interdependência entre desenvolvimento e competências.

Os subsistemas de T\&D e C\&S, teoricamente, deveriam estar em consonância, visto que, segundo os autores, o desenvolvimento do profissional, considerando treinamentos direcionados à sua área de atuação, acarreta na sua valorização e em consequente aumento na remuneração proporcionada aos servidores por meio de bonificações e promoções. Sem a abordagem da gestão por competência, dificilmente o desenvolvimento seria percebido de forma concreta, mensurado e recompensado de forma adequada. Porém, na prática, a discordância total dos respondentes da pesquisa ao item 5.2 aponta que, na UFC, não há um percentual motivador devidamente regulamentado e ofertado ao servidor que assume função de chefia, demonstrando o desalinhamento entre os subsistemas e destes em relação às diretrizes propostas pela gestão por competência.

Confrontando os resultados da pesquisa sobre o subsistema de avaliação de desempenho e o de C\&S, em dados qualitativos, o 
primeiro é percebido como instrumento meramente simbólico, aplicado sem compromisso por parte dos superiores, cumprindo basicamente as exigências legais que, inevitavelmente, impactam na progressão do servidor. A referida ferramenta que mensura o desempenho, da forma como é utilizada atualmente na UFC, proporciona legalmente a elevação na remuneração do servidor sem considerar o mérito real alcançado, desconsiderando completamente o que recomenda a gestão por competência, que, segundo Dutra (2010, p. 69) define desempenho como o "conjunto de entregas e resultados de determinada pessoa para a empresa ou o negócio", devendo este ser mensurado e devidamente recompensado para não causar insatisfações ou desmotivações aos servidores.

A discussão proposta nesta seção objetiva enfatizar pontos relevantes da pesquisa, considerando alguns dos inúmeros ângulos de visão propostos pela gestão por competência. Em linhas gerais, os dados quantitativos, com exceção dos dois primeiros itens do subsistema de remuneração ou C\&S e do terceiro item investigado no subsistema de R\&S, tendem a alinhar os subsistemas de gestão de pessoas da UFC às diretrizes propostas pela gestão por competência. Porém, na análise dos dados qualitativos, percebe-se de forma mais clara as dissonâncias apontadas pelos servidores que responderam a pesquisa em relação aos indicativos quantitativos encontrados.

Em síntese, no cenário traduzido pela pesquisa, indica-se a necessidade do desenvolvimento de esforços no gerenciamento do potencial humano da UFC para que se possa aproximá-lo ainda mais das diretrizes propostas pela gestão por competência e, consequentemente, promover a valorização do servidor e avanços na gestão estratégica da instituição.

\section{Conclusão}

As novas tendências para a gestão de pessoas proporcionam uma visão mais estratégica dessa atividade, direcionando o foco, anteriormente restrito ao controle, para o desenvolvimento sincronizado 
das pessoas e da organização, possibilitando o alcance simultâneo dos objetivos de ambos.

A possibilidade de alinhar o desenvolvimento das carreiras dos profissionais ao desenvolvimento da organização permite um ganho estratégico significativo, que impulsiona as instituições, ao mesmo tempo em que favorece a atuação profissional. Essa tendência, estimulada pela gestão por competência, está se consolidando nas organizações privadas e, por meio legal, inserindo-se também nas instituições públicas.

O interesse em pesquisar esse novo panorama levou à realização deste estudo. Inicialmente, a breve revisão bibliográfica proposta permitiu traçar um cenário teórico sobre a gestão de pessoas, destacando a gestão por competência e evidenciando sua aplicação no setor público. Foram enfatizados no apanhado teórico quatro subsistemas: recrutamento e seleção (R\&S), treinamento e desenvolvimento (T\&D), avaliação de desempenho, e remuneração ou cargos e salários (C\&S).

Embasado nas leituras realizadas, foi possível elaborar um questionário de pesquisa com o intuito de averiguar a operacionalização da gestão de pessoas atualmente desenvolvida na UFC. Atendendo ao problema proposto, o estudo desenvolvido apresentou a percepção do servidor técnico-administrativo lotado na Superintendência de Recursos Humanos (SRH) da UFC sobre quatro subsistemas de gestão de pessoas. Os resultados alcançados reportam às interações, bem como às dissonâncias encontradas entre os subsistemas anteriormente referidos e as diretrizes propostas pela gestão por competência.

Acrescenta-se que houve algumas dificuldades para a realização deste trabalho, como o difícil acesso a todos os servidores lotados na $\mathrm{SRH}$. A falta de um meio de comunicação eficaz com todos os servidores dificultou o desenvolvimento da pesquisa e fez com que a aplicação e o recolhimento dos questionários fossem realizados de forma presencial. Isso pode ter contribuído para o índice de retorno ter sido de $42,74 \%$ dos servidores lotados na $\mathrm{SRH}$, percentual que alcançou a amostra dessa pesquisa. 
Apesar das dificuldades, pode-se destacar que o subsistema de recrutamento e seleção (R\&S) apresentou, dentre os analisados, maior definição quanto ao seu alinhamento às diretrizes propostas pela teoria da gestão por competência. No outro extremo, apresentando maior dissonância na visão dos respondentes quanto ao seu alinhamento às diretrizes propostas pela gestão por competência, está o subsistema de remuneração ou cargos e salários (C\&S).

Acredita-se que, com os resultados da pesquisa, podem-se identificar, através do modelo de gestão por competência, possíveis melhorias na operacionalização da gestão de pessoas atualmente desenvolvida na UFC, especificamente para os quatro subsistemas abordados, influenciando positivamente a gestão estratégica dessa instituição de ensino superior e visando alcançar, satisfatoriamente, em seu ambiente interno, as práticas de gestão por competência e proporcionar aos seus servidores o que busca disponibilizar essa teoria, ou seja, a valorização profissional apoiada no desenvolvimento das competências e no desenvolvimento organizacional.

A pesquisa proposta merece ser ampliada, com o intuito de aprofundar os conhecimentos na área de gestão de pessoas em instituições públicas, visto que há a pretensão de se colocar um ponto final nas diversas análises e inferências passíveis de observação com os dados obtidos neste estudo. Portanto, indica-se a necessidade de um estudo mais apurado, com o intento de refinar as investigações propostas neste trabalho.

\section{Referências}

ABREU, Marina Maciel. A relação entre o Estado e a sociedade civil: a questão dos conselhos de direitos e a participação do Serviço Social. Serviço Social \& Movimento Social, São Luís, v. 1, p. 61-76, jul./ dez.1999.

ARAÚJO, Vinícius de Carvalho. A conceituação de governabilidade e governança, da sua relação entre si e com o conjunto da reforma 
do Estado e do seu aparelho. Texto para discussão n. 45. Disponível em: <http://www.enap.gov.br/index.php?option=content\&task=view\& id=259 . . Acesso em: 30 jan. 2007.

BARBOSA, Sandra Pires. Direito à informação e controle social da atividade econômica. Jus Navigandi, Teresina, ano 6, n. 51, 1 out. 2001. Disponível em: <http://jus.com.br/revista/texto/2078>. Acesso em: 4 jan. 2010.

BARRETT, Pat. Achieving better practice corporate governance in the public sector. AM Auditor General for Austrália. 2002. Disponível em: <http://www.anao.gov.au/uploads/documents/Achieving_Better_ Practice_Corporate_Governance_in_the_Public_Sector1.pdf $>$. Acesso em: 15 set. 2009.

BARROS, Maria Elizabeth Diniz. O controle social e o processo de descentralização dos serviços de saúde. In: INCENTIVO à participação popular e o controle social no SUS. Brasília, DF: Ministério da Saúde, Brasília, 1994. (Textos técnicos para conselheiros de saúde).

BORN, Rubens H. Governança e sustentabilidade: desafios para todos. In: FÓRUM BRASILEIRO DE ONGS E MOVIMENTOS SOCIAIS PARA O MEIO AMBIENTE E O DESENVOLVIMENTO. Governança ambiental internacional: perspectivas, cenários e recomendações. São Paulo: Vitae Civilis, 2007.

BRASIL. Constituição (1988). Constituição da República Federativa do Brasil: promulgada em 5 de outubro de 1988. Presidência da República Federativa do Brasil. Disponível em: <http://www.presidencia.gov.br/ legislacao>. Acesso em: 5 nov. 2009.

BRAVO, Maria Inês Souza. Desafios atuais do controle social no sistema único de saúde (SUS). Serviço Social \& Sociedade, São Luís, n. 88, nov. 2006.

CALLEGARI-JACQUES, Sidia M. Bioestatística: princípios e aplicações. Porto Alegre: Artmed, 2003. 255 p. 
CARNEIRO, Carla Bronzo Ladeira. Governança e Accountability: algumas notas introdutórias. Texto para Discussão $n^{0} 13$. Disponível em: <http://www.eg.fjp.mg.gov.br>. Acesso em: 30 jan. 2007.

CARVALHO, Antonio Ivo de. Conselhos de saúde: participação cidadã e social. Rio de Janeiro: FASE/IBAM, 1995.

CORREIA, Maria Valéria Costa. Que controle social? Os conselhos de saúde como instrumento. Rio de Janeiro: Fiocruz, 2000.

CORTES, S. M. V. Conselhos municipais de saúde: a possibilidade dos usuários participarem e os determinantes da participação. Ciência \& Saúde Coletiva, Rio de Janeiro, v. 3, n. 1, p. 5-17, 1998.

DALLABRIDA, V. R. (2004) ?Governança territorial e políticas públicas: para a institucionalização de uma prática de concertação públicoprivada? In: BÜTTENBENDER, P. L.; RIGHI, L. (Org.). Políticas públicas e saúde. ljuí: Ed. Unijuí, 2004. p. 10-25. (Cadernos Unijuí, série Gestão Pública, 3).

EIGEN, Peter. Corrupção é um desafio. In: SPECK, Bruno W. (Org.). Caminhos da transparência. Campinas, SP: Unicamp, 2002.

EISENHARDT, Katheleen M. Agency theory: an assessment and review. Academy of Management Review, Briarcliff Manor, v. 14, n. 1, p. 57-74, jan. 1989. Disponível em:< http://www.ppge.ufrgs.br/giacomo/ arquivos/ecop26/eisenhardt-1989.pdf >. Acesso em: 10 mar. 2010.

FREY, Klaus. Governança urbana e participação pública. RACEletrônica, Rio de Janeiro, v.1, n.1, p.136-150, jan./abr. 2007. Disponível em: <http://www.fag.edu.br/professores/pos/MATERIAIS/ MBA\%20em\%20Gest\%E3o\%20Empresarial/Material\%20Prof.\%20 Anderson/artigo\%20adm\%2018.pdf>. Acesso em: 3 mar. 2010.

GOHN, M.G. Conselhos gestores e participação sociopolítica. 3. ed. São Paulo: Cortez, 2007.

GONÇALVES, Alcindo. O conceito de governança. In: CONSELHO NACIONAL DE PESQUISA E PÓS-GRADUAÇÃO EM DIREITO, 
15., 2006, Manaus. Anais... Disponível em: <http://www.conpedi.org/ manaus/arquivos/Anais/Alcindo\%20Goncalves.pdf>. Acesso em: 15 mar. 2010.

HATCH, M. J. Organization theory: modern symbolic and postmodern perspectives. New York: Oxford University Press, 1997. cap. 2., p. 41-51. Disponível em: <http://ebooksfactory.org/ebooks/organizationtheory-modern-symbolic-and-postmodern-perspectives.html>. Acesso em: 5 set. 2009 .

JENSEN, Michael C.; MECKLING, William H. Theory of the firm: managerial behavior, agency costs and ownership structure. Journal of Financial Economics, New York, v. 3, n. 4, p. 305-360, Oct. 1976.

KAZANCIGIL, A. A regularização social e a governança democrática da mundialização. Traduzido por Luís Augusto Junges Lopes. In: MILANI, C.; ARTURI, C.; SOLINÍS, G. (Org.). Democracia e governança mundial: que regulações para o século XXI?. Porto Alegre: Ed. UFRGS/UNESCO, 2002. p. 47-62.

MILANI, C.; SOLINÍS, G. Pensar a democracia na governança mundial: algumas pistas para o futuro. In: MILANI, C.; ARTURI, C.; SOLINÍS, G. (Org.). Democracia e governança mundial: que regulações para o século XXI? Porto Alegre: Ed. Universidade/UFRGS/UNESCO, 2002. p. 266-291.

NASSAR, Silvia M.; WRONSCKI, Vilson R.; OHIRA, Masanao et al. SEstatNet: Sistema Especialista para o Ensino de Estatística na Web. Disponível em: <http://www.sestat.net>. Acesso em: 12 dez. 2011.

NOBRE, M. Participação e deliberação na teoria democrática: uma introdução. In: COELHO, V. S.; NOBRE, M. (Org.). Participação e deliberação: teoria democrática e experiências institucionais no Brasil Contemporâneo. São Paulo: Ed. 34, 2004. p. 21-40.

PEREIRA, Ricardo. M. O controle social na gestão pública: as funções de fiscalização e de ouvidoria dos Tribunais de Contas do Brasil. 2003. 
117 f. Dissertação (Mestrado Profissionalizante em Gestão Pública para o Desenvolvimento do Nordeste)- Universidade Federal de Pernambuco, Recife, 2003.

RAICHELIS, Raquel. Os conselhos de gestão no contexto internacional. Revista Pólis, São Paulo, n. 37, p. 41-45, 2000.

SECCHI, Leonardo. Modelos organizacionais e reformas da administração pública. Rev. Adm. Pública, Rio de Janeiro, v. 43, n. 2, abr. 2009. Disponível em <http://www.scielo.br/scielo.php?script=sci arttext\&pid=S0034-76122009000200004\&Ing=pt\&nrm=iso>. Acesso em: 8 jan. 2010.

SILVA, Gecilda Esteves. Os tribunais de contas e o controle social: a proposta de criação de uma ouvidoria para o tribunal de contas do Estado do Rio de Janeiro e sua importância no processo democrático fluminense. 2009. 122 f. Dissertação (Mestrado em Administração Pública)-Fundação Getúlio Vargas, Rio de Janeiro, 2009.

STREIT, R. E.; KLERING, L. R. Governança pública sob a perspectiva dos sistemas complexos. In: ENCONTRO DE ADMINISTRAÇÃO PÚBLICA E GOVERNANÇA - EnAPG, 2004, Rio de Janeiro. Anais... Rio de Janeiro: ANPAD, 2004.

WORLD BANK INSTITUTE. A decade measuring of quality the of governance. Governance Matters 2006. Worldwide governance indicators. New Annual Indicators and Underlying data. Washington, DC, 2006.

Artigo recebido em: 01/10/2012

Aprovado em: 04/04/2013 